\title{
PERCEPATAN PENYELESAIAN PERDA RTRW KABUPATEN INDRAGIRI HILIR SEBAGAI PEDOMAN PENATAAN RUANG
}

\author{
Rezky Kinanda \\ Dosen Prodi Teknik Sipil, Fakultas Teknik dan Ilmu Komputer, Universaitas Islam Indragiri \\ Email: alfa.boyone@gmail.com (korespondensi)
}

\begin{abstract}
Regional Regulation on Spatial Planning is an important element for each region because it contains binding regulations regarding spatial planning. This binding regulation will seek strict direction and strict limits on regional development. Regions that do not yet have local regulations on RTRW have the potential to experience conflicts, such as the seizure of spatial use areas by several sectors, furthermore each sector wants to be the main focus and become the most considered sector, then exploitation of space becomes uncontrolled because there are no strict rules governing boundaries. It is in the Regional Regulation on Regional Spatial Planning that local governments can get it all.

The drafting or completion of the Regional Regulation on Spatial Planning is not an easy thing to achieve in many regions in Indonesia. The proof is that there are still many regions that do not yet have local regulations on RTRW, including Indragiri Hilir Regency. This becomes the grid that Inhil Regency is threatened to get a negative effect from the absence of RTRW regulations.

This journal explains the important points why Inhil District needs a Regional Regulation on RTRW. This is also emphasized by the display of adverse effects if the RTRW regulation is not finished by the Inhil Government. This journal will also explain about any obstacles that the Inhil District Government might face in the effort to resolve the RTRW Perda.
\end{abstract}

Keywords: RTRW, Acceleration, Compilation, Government, Regency of Inhil

\begin{abstract}
Abstrak
Perda RTRW merupakan elemen penting untuk setiap daerah karena di dalamnya termuat aturan-aturan-aturan yang mengikat mengenai penataan ruang. Peraturan yang mengikat ini akan menjari arahan yang tegas dan batasan yang tegas dalam pembangunan daerah. Daerah yang belum memiliki perda RTRW berpotensi mengalami konflik, seperti perebutan wilayah pemanfaatan ruang oleh beberapa sektor, lebih jauh setiap sektor ingin menjadi fokus utama dan menjadi sektor yang paling diperhatikan, kemudia eksploitasi ruang menjadi tidak terkontrol dikarenakan tidak ada aturan tegas yang mengatur tentang batasan. Di dalam Perda RTRW lah pemerintah daerah bisa mendapatkan itu semua.
\end{abstract}

Penyusunan atau penyelesaian Perda RTRW bukanlah hal yang mudah tercapai oleh banyak daerah di Indonesia. Buktinya adalah masih sangat banyak daerah yang belum memiliki perda RTRW, termasuk Kabupaten Indragiri Hilir. Hal ini menjadi kisi-kisi bahwa Kabupaten Inhil terancam mendapat efek negative dari tidak adanya perda RTRW.

Jurnal ini menjelaskan poin-poin penting mengapa Kabupaten Inhil membutuhkan Perda RTRW. Hal ini juga dipertegas dengan ditampilkannya dampak-dampak buruk apabila perda RTRW tidak kunjung selesai dikerjakan Pemerintah Inhil. Jurnal ini juga akan menjelaskan tentang kendala-kendala apasaja yang mungkin akan dihadapi oleh Pemerintah Kabupaten Inhil dalam upaya untuk menyelesaikan Perda RTRW.

Kata kunci: RTRW, Percepatan, Penyusunan, Pemerintah, Kabupaten Inhil

\section{PENDAhUlUan}

Negara Indonesia memiliki undang- undang khusus tentang penataan ruang. Hal ini merupakan hal yang sangat baik untuk penataan ruang di Indonesia. Dengan adanya 
undang-undang khusus ini ada perhatian khusus pula.

Pelaksanan penataan ruang Indonesia berpedoman pada UU Nomor 26 Tahun 2007 tentang penataan ruang. Salah satu amanat undang-undang tersebut adalah setiap daerah harus memiliki perda RTRW. Hal ini demi meraih kemudahan dalam pembangunan daerah. Di Indonesia sendiri masih sangat banyak daerah yang belum memiliki perda RTRW yang menjadi salah satu sebab besar dari permasalahan pembangunan di daerah-daerah tersebut

Undang-undang tentang Penataan Ruang Nomor 26 tahun 2007 menetapkan kewajiaban kepada setiap wilayah provinsi dan juga kabupaten/kota untuk menyusun atau merevisi peraturan daerah tentang Rencana Tata Ruang Wilayah (RTRW). Penyusunan RTRW harus dibuat secara berjenjang. Dalam makna yang lain bahwa penyusunan RTRW Provinsi (RTRWP) harus berpijakan kepada RTRW Nasional (RTRWN) yaitu Peraturan Pemerintah Nomor 26 Tahun 2008 dan penyusunan RTRW kabupaten/kota harus berpijakan kepada RTRWN dan RTRW Provinsi.

Dalam proses penyusunan rencana tata ruang suatu wilayah pejabat pemerintah akan berhadapan dengan berbagai keinginan dan cita-cita pembangunan dari berbagai bidang. Setiap bidang ingin bidang mereka memiliki porsi yang mereka inginkan di dalam perda RTRW wilayah mereka. Misalnya bidang perkebunan ingin bidang perkebunan diberi prioritas tinggi dengan berbagai pertimbangan, begitu juga bidang pariwisata ingin bidang pariwisata diberi prioritas tinggi dengan berbagai pertimbangan. Hal ini tidak jarang menciptakan konflik tersendiri.

Permasalahan keuangan atau anggaran juga seringkali menjadi beban yang sangat menghambat pelaksanaan penyusunan RTRW dikarenakan penyusunan ini membutuhkan anggaran yang cukup besar. $\mathrm{Hal}$ ini tentu menjadi indikasi bahwa penyusunan perda RTRW kerap kali tidak menjadi prioritas dalam penganggaran daerah.

Hal ini juga terjadi di kabupaten Indragiri Hilir. Kabupaten Inhil hingga saat ini (2019) belum memiliki Perda RTRW. Dengan adanya Perda RTRW tentu akan memberikan rasa nyaman kepada pemerintah untuk mengatur dan menatata ruang wilayah Kabupaten Inhil. Tantangan-tantangan yang mungkin akan dihadapi Pemerintah Kabupaten Inhil juga cukup banyak seperti anggaran, usulanusulan yang belum ternegosiasikan, kepentingan-kepentingan berbagai pihak.

\section{PENTINGNYA RTRW UNTUK PEMBANGUNAN KABUPATAEN INDRAGIRI HILIR}

RTRW adalah pondasi terkuat dalam rencana pembangunan atau keijakan pembangunan. Di dalamnya berisi segala kebutuhan dasar untuk memutuskan kebijakan-kebijakan pembangunan. Hal ini berlaku untuk skala nasional sampai daerah. Termasuk kabupaten Indragiri Hilir.

Dalam Pepres Nomor 5 tahun 2010 tentang RPJMN, penataan ruang disebutkan adalah sebagai alat dalam pelaksanaan kebijakan pembangunan. $\mathrm{Hal}$ ini cukup membuktikan bahwa Pemerintah Pusat sangat yakin dengan RTRW sebagai pondasi pembangunan. Namun amat sangat disayangkan bahwa masih banyak daerah di Indonesia yang belum mampu merealisasikan Perda RTRW daerahnya dengan berbagai kendala. Hal ini menjadi penyebab terjadi banyak konflik di berbagai daerah.

Pertanyaan selanjutnya adalah kenapa RTRW menjadi pondasi kuat untuk kebijakan pembangunan ?

Pada dasarnya RTRW sendiri adalah sebuah kebijakan yang mengatur tentang penataan ruang di daerah tertentu. Banyak sekali pengertian tentang apa yang maksud dengan kebijakan publik dalam literaturliteratur politik. setiap pengertian menekankan pada hal yang berbeda-beda. Perbedaan dikarenakan masing-masing para ahli memiliki dasar keahlian yang berbedabeda.

Laswell dan Kaplan yang dikutip melalui buku Nugroho (2008) menekankan bahwa kebijakan publik adalah suatu proyek yang berorientasi pada tujuan-tujuan tertentu, nilai-nilai tertentu, dan praktik tertentu.

Sementara itu William N Dunn yang dikutip melalui buku Pasolong (2010), menegaskan bahwa kebijakan publik sebagai suatu rangkaian pilihan-pilihan yang saling berhubungan yang dibuat oleh lembaga atau pejabat pemerintah pada bidang-bidang yang menyangkut tugas pemerintahan, seperti pertahanan keamanan, energi, kesehatan, pendidikan, kesejahteraan masyarakat, kriminalitas, perekonomian dan lain-lain.

Definisi-definisi tersebut dapat dijadikan dasar pemikiran bahwa kebijakan pembangunan haru memiliki tujuan, arah, dan nilai yang hendak dicapai. Kesemuanya harus tertancap dengan kokoh melalui Perda Rencana Tata Ruang Wilayah. Didefinisikan pula bahwa di dalam kebijakan publik terkandung hubungan antar bidang seperti perekonomian, pertanian, keamanan, dll yang mana seluruhnya itu harus ditampung 
dalam suatu peraturan daerah yang dapat menghubungkan kebutuhan-kebutuhan dari berbagai bidang/sektor tersebut. Peraturan tersebut dalah RTRW.

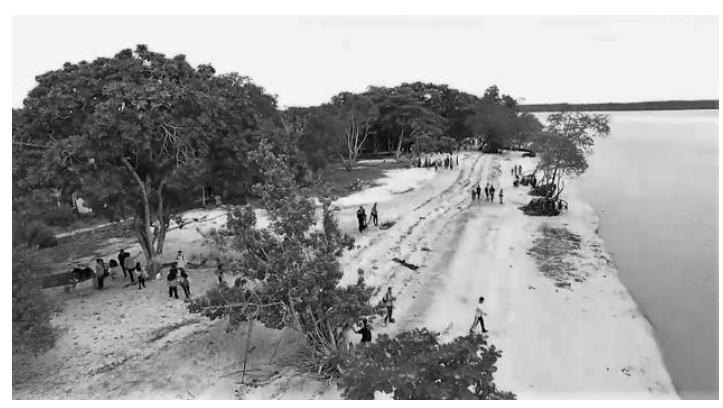

Gambar1. Kawasan Rekreasi Pantai Solop

RTRW adalah hasil perencanaan ruang pada wilayah yang merupakan kesatuan geografis beserta segenap unsur terkait yang batas dan sistemnya ditentukan berdasarkan aspek administratif (Permen PU No. 16/PRT/M/2009). Pada dasarnya ruang mempunyai keterbatasan, sehingga dibutuhkan peraturan yang dapat menata ruang agar dapat dimanfaatkan secara efektif. RTRW juga berfungsi untuk mengefektifkan pemanfaatan ruang dan mencegah terjadinya konflik antar bidang dalam proses pemanfaatan ruang. Serta menjaga masyarakat dari bahaya permasalahan lingkungan yang timbul akibat dari penyalahgunaan pemanfaatan ruang yang tidak sesuai dengan lokasi yang seharusnya.

Dengan adanya Perda RTRW, Pemerintah Kabupaten Inhil terbantukan untuk mencegah adanya konflik antar bidang di jajaran pemerintahan sendiri. sebagai contoh setiap bidang yang tadinya memiliki acuan peraturaannya sendiri berpotensi berkonflik dengan bidang lain yang juga memiliki peraturan sendiri, jika Pemerintah Kabupaten Inhil memiliki Perda RTRW maka konflikkonflik yang terkait tata ruang harus mengacu kepada Perda RTRW. Selain itu dengan adanya Perda RTRW, Pemerintah Kabupaten Inhil dapat mencegah terjadinya pembangunan di wilayah yang tidak sesuai, tidak cocok, dilarang, atau bahkan kawasan berbahaya dikarenakan Perda RTRW telah melewati berbagai kajian dan penelitian tentang ruang itu sendiri.

\section{DAMPAK NEGATIF TIDAK ADANYA PERDA RTRW TERHADAP PEMBANGUNAN}

Kendala-kendala perumusan rencana kebijakan sudah diprediksi oleh D.L. Weimer dan Aidan R.Vining $(1999 ; 398)$ dalam
Pasolong (2010;59). Menurut mereka ada tiga faktor umum yang mempengaruhi keberhasilan implementasi, yaitu:

a. Landasan teori, logika, hukum yang menjadi pondasi. Semakin kuat pondasi penyusunan RTRW maka semakin kuat dan cepat pula penyusunan Perda RTRW.

b. Kerja sama antar aktor. Penyusunan Perda RTRW harus dikerjakan dengan kerja sama yang baik antar pemangku kepentingan atau pemilik kekuasaan.

c. Ketersediaan sumber daya manusia yang memiliki kemampuan, komitmen untuk mengelola pelaksanaanya.

Pernyataan yang hampir serupa juga dijelaskan oleh Bappenas tentang dampakdampak yang bisa terjadi apabila suatu daerah belum memiliki perda RTRW. Adapun hal-hal yang harus diwaspadai oleh Pemerintah Kabupaten Inhil berdasarkan pernyataan Bappenas adalah:

a. Lamban atau terhentinya pembangunan Kabupaten Inhil karena kemungkinan Bupati khawatir akan mengeluarkan izin yang melanggar Undang-Undang Penataan Ruang

b. Gairah Investasi ke Inhil akan rendah karena investor khawatir atau ragu dengan arah kebijakan pembangunan yang tidak jelas.

c. Kerusakan lingkungan dikarenakan tidak ada batasan yang jelas dalam pelaksanaan eksploitasi sumberdaya alam yang dimiliki.

Hal-hal di atas bukanlah hal yang pasti akan terjadi terhadap pembangunan di Kabupaten Inhil akan tetapi dampak-dampak negative ini bisa menghantam daerah mana saja yang belum memiliki Perda RTRW termasuk Kabupaten Inhil.

\section{PENGHAMbat PENYUSUnAN PERDA RTRW}

Pemerintah Kabupaten Inhil harus memahami dan mengidentifikasi apa saja hal-hal yang dapat membantu mempercepat proses perda RTRW dan apa saja hal-hal yang dapat menghambat laju perda RTRW. Hal ini berguna untuk menyusun strategi percepatan Perda RTRW Kabupaten Inhil.

Jika mengambil pendapat D.L. Weimer dan Aidan R.Vining $(1999 ; 398)$ dalam Pasolong $(2010 ; 59)$ dan menghubungkannya dengan percepatan Perda RTRW Kabupaten 
Inhil maka ada tiga faktor umum yang mempengaruhi keberhasilan kebijakan, yaitu:

a. Landasan teori, logika, hukum, serta hal lain yang menjadi pijakan dalam penyusunan Perda RTRW Kabupaten Inhil, semakin tegas dan kuat landasan yang dipakai semakin kuat dan cepat pula kebijakan direncanakan dan dilaksanakan

b. Kerjasama antar pejabat dan antar sektor di Kabupaten Inhil harus terjalin kerjasama yang kuat antar dinas terkait bahkan sampai kepada anggota DPRD.

c. Ketersediaan sumber daya manusia yang berkualitas. Pemerintah Kabupaten Inhil harus menempatkan SDM yang berkualitas dan cocok dengan bidang yang dihadapinya sehingga pekerjaan akan semakin efektif.

Berdasarkan teori diatas dan informasi dari Bappenas maka dapat disimpulkan bahwa faktor-faktor yang wajib menjadi perhatian Pemerintah Kabupaten Inhil, yaitu:

a. Tidak singkronnya implementasi antar sektor atau bidang di Kabupaten Indragiri Hilir dalam pemanfaatan ruang bisa menjadi penyebab konflik pemanfaatan ruang. Misalnya sektor pertanian, perkebunan, pertambangan, dan hutan berpotensi saling berebut wilayah kekuasaan pemanfaatan ruang dikarenakan tidak ada Perda RTRW Kabupaten Inhil

b. Dalam hal substansi berpotensi terjadi tabrakan aturan antar sektor dan bidang di Kabupaten Inhil dimana setiap sektor mengacu kepada perundang-undangan mereka sendiri yang membuat Undangundang Penataan Ruang sulit menjadi acuan.

c. Kualitas Sumber Daya Manusia (SDM). Terjadi banyak mutasi/rotasi SDM di pemerintahan yang tidak cocok dengan kompetensinya. Ditambah lagi daerah belum memunyai prosedur untuk transfer of knowledge, sehingga bidang yang terisi oleh pejabat baru akan menghadapi hambatan untuk menguasai kondisi di jabatannya tersebut .

d. Koordinasi antar Lembaga Pada umumnya, Komunikasi rutin BKPRD yang membahas khusus mengenai integrasi antara rencana tata ruang dengan rencana pembangunan harus ditingkatkan hal ini guna menambah laju percepatan perda RTRW

e. Kendala Regulasi Terkait dengan regulasi dan kebijakan Pemerintah Pusat, ada beberapa hal yang dianggap dapat menjadi kendala, yaitu:

1) Dinamisnya perumusan peraturan baru dari Pemerintah Pusat memengaruhi penyusunan RTRW Daerah

2) Kebijakan mekanisme penyusunan peta dalam perumusan RTRW yang mengharuskan Daerah untuk melakukan verifikasi peta ke BIG di Cibinong. Kebijakan ini justru menjadi hambatan besar dalam penyusunan RTRW, sehingga membutuhkan anggaran dan waktu yang tidak sedikit. Hal ini haruslah menjadi bahan evaluasi sehingga memungkinkan verivikasi dilakukan pihak provinsi saja.

3) Adanya kebijakan dari Kementerian ATR yang menginstruksikan untuk mengakomodasi Nawacita dalam RTRW Provinsi.

4) Belum adanya pedoman dari Pemerintah Pusat untuk penyusunan Rencana Tata Ruang Kawasan Strategis Provinsi/Kabupaten/Kota, serta pedoman untuk peninjauan kembali RTRW.

f. Kendala Periodisasi juga kerap menjadi hambatan. Terdapat ketidaksingkronan periode antara RTRW dengan RPJPD dan RPJMD.

g. Kendala Faktor Politis dan Ketersediaan Anggaran . Telambannya Perda RTRW, RDTR, maupun RPJMD di kawasan kekuasaan legislatif (DPRD) dapat disebabkan oleh faktor politik.

\section{STRATEGI \\ PERCEPATAN PENYUSUNAN PERDA RTRW}

Berdasarkan penjelasan-penjelasan diatas maka dapat dihasilkan beberapa starategi yag bisa dijadikan pertimbangan oleh Pemerintah Kabupaten Inhil. Terdapat 4 variabel yang harus menjadi perhatian Pemerintah Kabupaten Inhil. Variablevariabel ini dikuatkan dengan pendapat dari Edward III dalam agustino (2012) yang mana variable-variabel ini memiliki keterkaitan satu 
dengan yang lain dan harus dipegang erat untuk mempercepat Perda RTRW Kabupaten Inhil.

a. Komunikasi.

Pemerintah Kabupaten Inhil harus memperhatikan komunikasi antar sektor, dinas, dan pejabat. Ada tiga indikator yang dapat digunakan dalam mengukur keberhasilan aspek komunikasi ini, yaitu :

1) Transmisi, yaitu penyaluran komunikasi yang baik agar penyusunan perda RTRW ini bisa berjalan dengan komukasi yang lancer dan tidak terjadi kesalahpahaman.

2) Kejelasan informasi yang disampaikan dalam komunikasi juga harus jelas, tidak ambigu.

3) Konsistensi informasi yang disampaikan, yaitu perintah ataupun informasi yang diberikan harus konsisten sehingga tidak terjadi perubahan mendadak tanpa ada konfirmasi.

b. Sumberdaya

Komunikasi yang baik membutuhkan sumber daya yang baik pula. Edward III dalam Agustino (2012:152) menyatakan bahwa ada poin-poin yang harus diperhatikan untuk memenuhi kebutuhan sumberdaya ini, yaitu :

1) Sumber Daya Manusia yang Berkualitas

2) Landasan Peraturan yang jelas

3) Struktur dan wewenang yang kuat, jelas, dan tidak tumpang tindih

4) Fasilitas yang cukup dalam pelaksanaannya

c. Disposisi

Disposisi adalah sikap dan komitmen aparat pelaksana terhadap penyelesaian atau penyusunan Perda RTRW Kabupaten Inhil. Jika pelaksana memiliki disposisi yang baik, maka penyusunan RTRW ini juga menjadi efektif dan efesien.

d. Struktur Organisasi

Struktur birokrasi berkenaan dengan kesesuaian organisasi birokrasi yang menjadi penyelenggara penyusunan Perda RTRW. Di Indonesia sering terjadi inefektivitas implementasi kebijakan karena kurangnya koordinasi dan kerjasama diantara lembagalembaga Negara dan/atau pemerintah.

\section{TINDAKAN NYATA}

Selain berpegang Teguh pada variable diatas tentunya Pemerintah Kabupaten Indragiri HIlir membutuhkan langkahlangkah nyata. Berikut beberapa langkah nyata yang bisa diambil Pemerintah Kabupaten Indragiri Hilir. Langkah atau strategi ini diharapkan bisa menjadi pertimbangan dalam menyusunan percepatan Perda RTRW Kabupaten Indragiri Hilir.

a. Dengan tujuan memperkuat landasan penyusunan RTRW Kabupaten Inhil maka harus diperkuat juga arahan Penyusunan Perda RTRW ini di dalam agenda Pemerintahan Kabuoaten Indragiri hilir. Diantaranya adalah dengan memasukan Penyelesaian RTRW sebagai salah satu fokus lewat rencana kerja pemerintah (RKP) dengan kata lain memasukan penyelesaian RTRW sebagai kegiatan prioritas dalam rencana pembangunan Kabupaten Indragiri Hilir.

b. Singkronisasi perundang-undangan berbagai sektor terkait dengan sektor penataan ruang Kabupaten Inhil. Setiap sektor punya perundangan sendiri-sendiri sehingga diperlukan inventarisasi perundangan dan inventarisasi data dan informasi terkait

konflik/ketidaksesuaian/pertentangan antar sektor.

c. Dengan menjadikan penyusunan atau penyelesaian RTRW sebagai salah satu fokus utama maka dari ini seharusnya akan terjadi peningkatan dalam hal teknis seperti peningkatan kualitas dan kuantitas SDM, kucuran dana yang meningkat, dan peningkatan hal teknis lainnya.

d. Rapat Rutin aktor pemangku kepentingan atau pemegang kekuasaan agar proses percepatan terus bisa dipantau dan digenjot lebih baik lagi dalam frekuensi waktu yang rutin dan banyak.

e. Sosialisasi, pelatihan, atau workshop kepada seluruh elemen atau aktor yang terlibat. Materi yang diangkat adalah pentingnya Perda RTRW dan keharmonisan hubungan dalam penyusunannya. Hal ini guna mengangkat moral dan semangat seluruh pihak agar peduli dengan Penyusunan Perda RTRW Kabupaten Indragiri Hilir. 


\section{Penutup}

Kesadaran akan pentingnya RTRW harus tertanam di dada para pemangku kepentingan dan pejabat terkait di Kabupaten Indragiri Hilir. Kesadaran bahwa RTRW ini adalah elemen penting dalam penataan ruang. RTRW akan membawa kebaikan pembangunan Kabupaten Indragiri Hilir serta bisa menjadi pencegah dari konflik serta keburukan pelanggaran tata ruang.

Diharapkan informasi dan usulan dari jurnal ini dapat menjadi bahan pertimbangan bahwasanya RTRW adalah hal yang sangat penting untuk kemajuan pembangunan Kabupaten Indragiri Hilir. Jurnal ini pula tidak terlepas dari kekurangan dan diharapkan akan dilakukan penelitian lebih mendalam untuk menyempurnakan kekurangan dari jurnal ini.

Keterbatasan Penelitian dan Penelitian Lanjutan

a. Kendala-kendala yang dihadapi dalam penyusunan Perda RTRW pada jurnal ini bersifat kajian pustaka dari buku para ahli dan dokumen resmi Negara. Diharapkan dilakukan kajian lebih lanjut dan lebih khusus kepada Kabupaten Indragiri Hilir melalui berbagai metode yang lebih mendalam pula.

b. Dampak-dampak yang dihadapi jika tidak memiliki Perda RTRW pada jurnal ini bersifat kajian pustaka dari buku para ahli dan dokumen resmi Negara. Diharapkan dilakukan kajian lebih lanjut dan lebih khusus kepada Kabupaten Indragiri Hilir melalui berbagai metode yang lebih mendalam pula.

c. Usulan-usulan yang dipaparkan pada jurnal ini baru bersifat teoritis sehingga diharapkan kajian berikutnya harus lebih khusus menggali informasi dari kondisi eksisting di kabupaten Indragiri Hilir.

\section{Daftar Pustaka}

[1] Agustino, Leo. 2012. Dasar-Dasar Kebijakan Publik. Alfabeta: Bandung

[2] Aswicaksana. 2010: 'Percepatan Penyelesaian Perda rtrw Daerah Sebagai Upaya Penyelenggaraan Penataan Ruang yang Lebih Baik', Jakarta : Bappenas

[3] Dunn, William N., 2003. Pengantar Analisis Kebijakan Publik. Gadjah Mada University Press, Yogyakarta.

[4] Edward III, George C. 1980, Implementing Public Policy,
Congressional Quarterly Press, Washington.

[5] Pasolong, Harbani. 2010. Teori Administrasi Publik, Alfabeta, Bandung.

[6] Weimer, D.L. \& Aidan R. Vining. 1998. Policy Analysis: Concept and Practice. New Jersey: Prentice-Hall, Inc 